\title{
Human rights trauma and the mental health of West Papuan refugees resettled in Australia
}

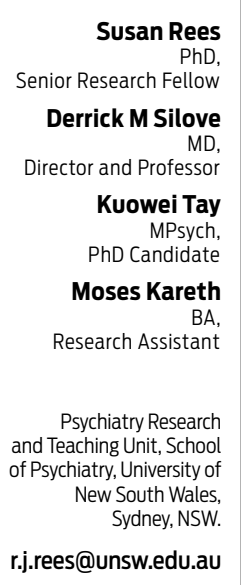

MJA 2013; 199: 280-283 doi: 10.5694/mjal2.11651

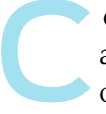

oncerns have been raised about human rights violations occurring over an extended period of time in West Papua, although the flow of information is limited because of restrictions in access to the province. ${ }^{1-5}$ The territory occupies the western half of the New Guinea landmass and was a Dutch colony until 1966, when it was annexed by Indonesia after a referendum that was widely regarded as invalid. ${ }^{2}$ Since then, there has been an ongoing resistance war aimed at achieving independence for West Papua, with reports of human rights violations including murder, torture and other forms of abuse. In addition, the indigenous population live in conditions of socioeconomic underdevelopment in spite of the wealth generated by the exploitation of natural resources. ${ }^{1-4}$

The ongoing conflict has resulted in a number of refugees seeking asylum in neighbouring Papua New Guinea and Australia. Refugees have been targeted directly by the Indonesian military for having an association with the independence movement. 2,3,5,6 Most refugees are settled in Papua New Guinea, given that the onward trip to Australia is fraught with danger and uncertainty about achieving residency status.

The existing community of West Papuan refugees in Australia have permanent residency visas, the right to work and to health and social services, including English language training.

To our knowledge, there have been no systematic reports to date on the traumas, stresses and mental health of West Papuan refugees living in Australia. ${ }^{2}$ In this study we aimed to explore West Papuan refugees' reported exposure to human rights violations and other traumas in West Papua, their ongoing living difficulties, particularly those associated with separation from their homeland, and manifestations of mental distress consistent with these experiences.

Objectives: To document the extent and nature of human rights violations and other traumatic events reported by West Papuan refugees resettled in Australia and to assess trauma-related psychological disorders, distress and disability.

Design and setting: Australian-based sample, mixed-methods design with 44 participants, conducted in Australia between October 2007 and November 2010 in communities in North Queensland and Melbourne.

Participants: West Papuan refugees aged 18 years and over (88\% response rate).

Main outcome measures: Post-traumatic stress disorder (PTSD) symptoms (Harvard Trauma Questionnaire) and premigration potentially traumatic events (PTEs), psychological distress (Kessler Psychological Distress Scale [K10]), post-migration living difficulties, days out of role.

Results: Of the 44 West Papuan refugees, 40 reported one or more PTE, including inability to access medical care for family (40), lack of food and water (39) and lack of access to medical treatment (38). The most frequent postmigration stressors were separation from and worries about family members remaining in West Papua (43) and being unable to return home in an emergency because of ongoing conflict (41). Twenty-six participants reached a lower threshold for PTSD symptoms of 2.0 , and 13 reached the clinical threshold of 2.5. Fourteen reported severe psychological distress.

Conclusions: West Papuan refugees resettled in Australia report a wide range of premigration PTEs including human rights violations, as well as symptoms of PTSD and distress. The data add to concerns about the state of human rights and mental health among West Papuans.

\section{Methods}

The study was undertaken between October 2007 and November 2010. We adopted a mixed-methods approach, combining mental health measures and in-depth interviews, following a procedure that is consistent with the Consolidated criteria for reporting qualitative research (COREQ). ${ }^{7}$ We were guided by the theoretical perspective of pragmatism, affording equal weighting to the quantitative and qualitative data, ${ }^{8,9}$ and drawing on the principles of complementarity, where quantitative and qualitative methods are used to address different facets of the same problem, and confirmation, where the results of two methods are examined to assess for convergence, dissonance or ambiguity. ${ }^{8}$

\section{Study sample}

West Papuan leaders estimated that there were 60 refugees residing in Australia, forming our target group. We applied a snowball recruitment method, with early participants assisting in locating and approaching other members of the West Papuan community who had arrived as refugees. We achieved an $88 \%$ response rate, with 37 men and 7 women participating. Of the total 44 participants, 28 resided in Melbourne, and 16 in North Queensland; however, members of the community tended to move between the two locations for work purposes. The gender balance reflects the pattern of migration, with more men leaving West Papua as refugees.

Six of those approached refused interviews because of fear of reprisal, and four returned to West Papua before their interview. We could not contact the remaining six identified West Papuan refugees. Given that several participants did not know their date of birth, we derived broad age groupings as follows: 19-30 years (14 participants), 31-40 years (17), 41-50 years (six) and 51 years and over (seven). Twenty-eight participants were single, 11 were married and four had been married previously. Sixteen participants were stu- 
dents, 20 were employed in agriculture (mainly on banana plantations), and the remainder were unemployed. To ensure protection of identities, we did not record actual dates of arrival in Australia. Nevertheless, we could confirm that most participants arrived in Australia during two migration waves (1980-1986 and 1995-1996), with a small number resettled in the 1970s.

\section{Measures}

The Harvard Trauma Questionnaire (HTQ) is the most widely used measure of post-traumatic stress disorder (PTSD) in the refugee and post-conflict mental health field. ${ }^{10}$ Two threshold scores have been applied in the literature: the commonly-used clinical cut-off of 2.5 and the lower cut-off of 2.0. ${ }^{11}$ The measure also lists commonly experienced human rights-related traumas and related severe stresses (scored 0 for no, 1 for yes), yielding a summary score of premigration potentially traumatic events (PTEs). Based on preliminary focus group data, we adapted the list to include items relevant to West Papua. Similarly, the PostMigration Living Difficulties (PMLD) checklist was modified to assess postmigration stresses relevant to the experiences of West Papuan refugees in Australia over the past 12 months. ${ }^{12}$ The PMLD provides a summary score of total living difficulties (sum of items each scored 1 if causing severe or very severe stress).

The Kessler Psychological Distress Scale (K10) is a self-reported measure of psychological distress used extensively across countries, and provides a proxy index of depression and general mental disorder. ${ }^{13,14}$ We applied the established thresholds of mild (20-24), moderate (25-29) and severe distress (>30) to provide gradations of symptoms within the community.

We applied an index of days out of role as a measure of disability, based on the number of days, out of the past 30 days, in which health-related problems prevented participants from conducting their usual daily activities. ${ }^{15}$

\section{Procedure}

The quantitative measures were applied across the whole sample. Qualitative data were collected in two phases. Phase 1, in the North Qld group, included in-depth open-ended interviews focusing on experiences before, during and after migration. Phase 1 also explored indigenous concepts and descriptions of idioms of distress reported elsewhere. ${ }^{6}$ From Phase 1 data, we derived themes relevant to the stressors and traumas experienced, which formed the basis of a semi-structured interview used in Phase 2 with West Papuans living in Melbourne.

Interviews were undertaken by West Papuan or Australian members of the research team. Australian interviewers not fluent in Bahasa Indonesia worked in parallel with West Papuan collaborators acting as translators. Participants were interviewed in their homes or at other private locations. Interviews extended up to 2 hours and included short breaks. Consent was obtained in accordance with ethics clearance from James Cook University, where the first author was employed at the beginning of the project.

\section{Statistical analyses}

We provide descriptive data (counts, means, SD) for premigration (human rights-related) traumas, postmigration stresses and measures of mental health. Pearson correlation coefficients are reported for associations between mental health indices and days out of role. Statistical analyses were undertaken using IBM SPSS Statistics version 20 .

\section{Mixed-methods data analysis}

NVivo version 9 (QSR International) was used to derive metathemes and subthemes from the qualitative data to illustrate the interaction of stresses and traumas with mental health symptoms. ${ }^{16-18}$ All data were collected and recorded systematically, with triangulation of results achieved by cross-verification of findings across research methods (qualitative interviews, quantitative measures), thereby providing additional validity for the findings. ${ }^{19}$

\section{Results}

\section{Human rights violations and other PTEs}

Most of the West Papuan refugees (40/ 44) reported experiencing one or
Reported frequency of potentially traumatic events (PTEs) and severe traumas before migration, and living difficulties after migration

\section{Premigration PTEs}

Family members sick and unable to get medical treatment Lack of food and water

Lack of access to medical treatment

Forced separation from family members

Witnessing murder of family or friend

Disappearance of family member

Lack of shelter

House burnt down by Indonesian militia

Physical assault

Experience of combat situation

Witnessing murder of stranger

Torture

Imprisonment

Serious injury

Postmigration living difficulties

Separation from family in homeland

Worries about family in homeland

Unable to return home during emergency because of ongoing conflict

Communication difficulties

Poor access to favourite foods

Discrimination

Loneliness and boredom

Fears of repatriation

Difficulties in employment

Isolation

Poverty

Difficult work conditions

Delays in processing asylum application

Limited work rights

Difficulties in interviews with immigration officials

Limited government assistance in welfare

Worries about lack of access to treatment for health-related problems

Poor access to dental care

Poor access to counselling services

Being in detention

Conflict with immigration authorities

Poor access to long-term medical care

Poor access to emergency medical care

Limited support from charities or non-government organisations

more categories of PTEs relating to their lives in West Papua (Box). In order of prevalence, the PTEs reported included family members being sick and unable to access health care (40/ $44)$, lack of food or water $(39 / 44)$, personally being sick and unable to access health care (38/44), forced separation from family members (35/44), witnessing the murder of a family 
member or friend (34/44), lack of shelter (31/44) disappearance of family members (33/44), having one's house intentionally burnt down by Indonesian militia or police (29/44), physical assault (27/44) experiencing a combat situation (26/44) and torture (21/44).

Describing the range and contemporary relevance of these traumas, a participant said:

People don't know much about West Papua, there is a lack of interest in West Papuan issues. They don't know about 10 to 15 students who support West Papuan independence every week being taken to prison to be tortured.

and

... they [Indonesian military] take over my country, kill, rape, and steal our property like gold, oil, timber, copper and fish.

\section{Postmigration living difficulties}

The most prevalent stresses faced by West Papuan refugees while living in Australia were associated with unresolved conflict in their homeland, including forced separation from family members residing in the home country (43/44), associated worries about the safety and wellbeing of family members (43/44), and not being able to visit their homeland in times of emergency because of ongoing conflict (41/44) (Box). Sharing the experience of most, a participant explained:

I feel sad and grieving because of the loss of land, separation from family, and the abuse of Papuans, I feel helpless, I can't help my family back home, and we have lost everything.

\section{PTSD symptoms}

Most of the participants (26/44) reached the lower threshold for PTSD symptoms of 2.0 , and 13 participants met the clinical threshold of 2.5. Commonly reported symptoms of post-traumatic stress included repeated nightmares and memories associated with traumatic experiences, flashbacks, periods of memory impairment, persistent avoidance of triggers of trauma events, reduced emotional responsiveness and social detachment, as well as a heightened state of arousal.

Reminders from the homeland triggered intrusive memories of past trauma:

I get very frightened when I hear news from home like family member pass away or Indonesian army killed one of my family members which reminded me of what happened before...

\section{$\mathrm{K} 10$ results}

According to the conventional cut-off scores for the K10, 21 participants had mild psychological distress, 11 had moderate psychological distress, and 14 had severe psychological distress. Over 30 participants reported prominent symptoms indicative of depression and anxiety, including feeling everything was an effort, that nothing could cheer them up, and feeling restless and fidgety. Explaining the significance of the trauma and loss to ongoing symptoms of distress, a participant said:

I feel sad because of what Indonesian military has done in WP [West Papua] ... because my family passed away back home; because I can't help my family back home; because people lost everything back home.

\section{Disability}

PTSD symptoms (mean, 2.05; SD, 0.62 ) were associated with the mean days out of role in the past month (mean, 3.71; SD, 5.76; Pearson correlation coefficient $[r]=0.375, P=0.01$ ), with psychological distress showing a trend in the same direction (mean, 24.25; SD, 8.90; $r=0.229, P=0.15)$.

\section{Discussion}

Our study is the first mental health inquiry worldwide to document reported human rights violations and other PTEs and stressors experienced in the homeland, difficulties after migration, and trauma-related mental symptoms among refugees from West Papua. The data indicate that West Papuans report exposure to a wide array of human rights violations and other traumatic events in their home country, comparable to the experiences of other refugee groups exposed to conditions of mass conflict. ${ }^{20,21}$
Commonly reported traumas in our survey included lack of food or water, witnessing the murder of a family member or friend, having family members disappear, houses being intentionally burnt down and being involved in combat. Being unable to access medical care for oneself or one's family in an emergency was the most widely experienced stressor, endorsing other reports identifying the problem of access to adequate health services for the indigenous people of West Papua. ${ }^{2-4}$

Importantly, refugees reported that family, friends and others were being exposed to similar traumas in their contemporary lives in West Papua. It is noteworthy that $48 \%$ of our sample reported being tortured, a form of abuse that is particularly potent in generating severe and persisting PTSD. ${ }^{20}$ The rate of exposure to torture is notable, given that an extensive systematic review of refugee research has shown that $21 \%$ of participants in 84 epidemiological surveys among refugees and conflict-affected societies worldwide reported being subjected to this form of abuse. ${ }^{20}$

There is accruing evidence that postmigration stressors can interfere with successful settlement among refugees. $^{22,23}$ It was notable that the most highly reported postmigration stresses related to ongoing conflict in the homeland and anxieties about the safety and security of family remaining behind. Many refugees indicated that they would not be able to overcome their state of distress until the conflict in their home country ended and they were assured of the safety of their families.

The prevalence of symptoms of PTSD and psychological distress are comparable to those reported by refugee and conflict-affected populations in many other countries worldwide. ${ }^{20}$ Nevertheless, a number of refugees indicated that in spite of their symptoms, they made efforts to continue working and interacting socially with their compatriots. This commitment to maintain their level of functioning may account in part for the relatively low correlation between mental health symptoms and the days-outof-role index.

The limitations of the study are the small sample size and issues relating 
to its representativeness. Privacy considerations limited us in gathering sensitive data such as the actual dates of arrival of refugees in Australia. The sample was restricted to refugees in Australia, so the prevalence of trauma and mental health symptoms cannot be generalised to the whole population of West Papua. We do not know if non-participants differed from respondents on key indices of trauma and mental health, a potential source of bias. In addition, we cannot dismiss the possibility of reporting bias given that several of the participants had taken a stand against the occupation of West Papua. We did not recalibrate the HTQ or K10 to norms for this culture, so international cut-off scores should be regarded as only broadly indicative of incremental levels of distress.

In summary, our findings shed light on the extent and nature of reported human rights violations and other traumatic events and consequent mental distress among West Papuan refugees resident in Australia. The results are particularly concerning given recent media reports that there are ongoing human rights violations occurring in a territory that is one of Australia's closest neighbours. ${ }^{5}$ The data will be of value in alerting clinicians treating West Papuan refugees to underlying trauma and mental distress in this population that may not be readily revealed. More broadly, our research may provide impetus to initiating further and larger studies investigating the range of traumas and mental health problems of West
Papuans both inside the territory and living as refugees in other countries.

Acknowledgements: This study was supported by a program grant from the National Health and Medical Research Council. The views expressed are those of the authors alone.

Competing interests: No relevant disclosures.

Received 10 Nov 2012, accepted 18 Jun 2013.

1 Rees S, Silove D. Speaking out about human rights and health in West Papua. Lancet 2007; 370: 637-639.

2 Human Rights Watch. Out of sight: endemic abuse and impunity in Papua's Central Highlands. New York: Human Rights Watch, 2007. http://www.hrw.org/reports/2007/ papua0707/index.htm (accessed Jun 2013).

3 Wenda B. Everyone profits from West Papua, except for Papuans. The Guardian 2012; Oct 12. http://www.guardian.co.uk/commentisfree/ 2011/oct/12/west-papua-striking-minersindonesia (accessed Jun 2013).

4 Cooper H, Main L. Australia faces link to West Papua torture. 7.30 Report (ABC TV) 2012; 28 Aug. http://www.abc.net.au/7.30/content/2012/ s3578010.htm (accessed May 2013).

5 Rees SJ, van de Pas R, Silove D, Kareth M. Health and human security in West Papua. Med J Aust 2008; 189: 641-643.

6 Rees S, Silove D. Sakit Hati: A state of chronic mental distress related to resentment and anger amongst West Papuan refugees exposed to persecution. Soc Sci Med 2011; 73: 103-110.

7 Tong A, Sainsbury P. Craig J. Consolidated criteria for reporting qualitative research (COREQ): a 32item checklist for interviews and focus groups. Int J Oual Health Care 2007: 19: 349-357.

8 Greene JC, Caracelli VJ, Graham WF. Toward a conceptual framework for mixed-method evaluation designs. Educ Eval Policy Anal 1989; 11 : 255-274. doi: 10.3102/01623737011003255.

9 Creswell J, Plano Clark V, Gutmann M, Hanson W. Advanced mixed methods research designs. In: Tashakkori A, Teddlie C, editors. Handbook of mixed methods in social and behavioural research. Thousand Oaks, Calif: Sage, 2003: 209-240.

10 Mollica RF, Caspi-Yavin Y, Bollini P, et al. The Harvard Trauma Questionnaire. Validating a cross-cultural instrument for measuring torture, trauma, and posttraumatic stress disorder in Indochinese refugees. J Nerv Ment Dis 1992; 180: $111-116$.

11 Mollica RF, Sarajlic N, Chernoff M, et al. Longitudinal study of psychiatric symptoms, disability, mortality, and emigration among Bosnian refugees. JAMA 2001; 286: 546-554.

12 Schweitzer R, Melville F, Steel Z, Lacherez P. Trauma, post-migration living difficulties, and social support as predictors of psychological adjustment in resettled Sudanese refugees. Aust N Z J Psychiatry 2006; 40: 179-187.

13 Kessler RC, Andrews G, Colpe LJ, et al. Short screening scales to monitor population prevalences and trends in non-specific psychological distress. Psychol Med 2002; 32: 959-976.

14 Andrews G, Slade T. Interpreting scores on the Kessler Psychological Distress Scale (K10). Aust N Z J Public Health 2001; 25: 494-497.

15 Slade T, Johnston A, Oakley Browne MA, et al. 2007 National Survey of Mental Health and Wellbeing: methods and key findings. Aust NZ J Psychiatry 2009; 43: 594-605.

16 Johnson RB, Onwuegbuzie AJ. Mixed methods research: a research paradigm whose time has come. Educ Researcher 2004; 33: 14-26. doi: 10.3102/0013189X033007014.

17 Torrance $\mathrm{H}$. Triangulation, respondent validation, and democratic participation in mixed methods research. J Mixed Methods Res 2012; 6: 111-123. doi: $10.1177 / 1558689812437185$.

18 McDowell I, MacLean L. Blending qualitative and quantitative study methods in health services research. Health Informatics J 1998; 4: 15-22. doi: $10.1177 / 146045829800400103$.

19 Kitto SC, Chesters J, Grbich C. Quality in qualitative research. Med J Aust 2008; 188: 243-246.

20 Steel Z, Chey T, Silove D, et al. Association of torture and other potentially traumatic events with mental health outcomes among populations exposed to mass conflict and displacement: a systematic review and metaanalysis. JAMA 2009; 302: 537-549.

21 Hauff E, Vaglum P. Organised violence and the stress of exile. Predictors of mental health in a community cohort of Vietnamese refugees three years after resettlement. Br J Psychiatry 1995; 166: 360-367.

22 Silove D, Coello M, Tang K, et al. Towards a researcher-advocacy model for asylum seekers: a pilot study amongst East Timorese living in Australia. Transcult Psychiatry 2002; 39: $452-$ 468. doi: 10.1177/136346150203900404.

23 Rees S, Silove D, Kareth M. Dua sakit (double sick): trauma and the settlement experiences of West Papuan refugees living in North Queensland. Australas Psychiatry 2009; 17 Suppl 1: S128-S132. 